\title{
The bizarre appearance of intrathoracic extramedullary hematopoiesis during an endoscopic ultrasound examination
}

A 61-year-old man was referred for evaluation of bilateral, intrathoracic, paravertebral masses suspicious for malignancy ( $\triangleright$ Fig. 1 a,b). The lesions had been incidentally detected in the thoracic slices of an abdominal computed tomography (CT) performed to investigate suspected kidney stones. The patient had no thoracic complaints and had an unremarkable past medical history. Given the proximity to the esophagus, an endoscopic ultrasound (EUS) with bronchoscope was performed to rule out lung cancer. It showed the right-sided lesion as a $5.5-\mathrm{cm}$, heterogeneous mass characterized by the bizarre alternation of thick linear hyperechoic and iso-hypoechoic areas ("zebralike” appearance) ( $\triangleright$ Video 1 ). Several passes with a 22-gauge needle were performed without any complication, and the pathologic examination of both tissue cores and smears led to the diagnosis of an intrathoracic extramedullary hematopoiesis ( $\mathbf{F i g . 2 a , b ) . ~ H e m a t o l o g i c ~}$ laboratory tests were performed and an underlying beta thalassemia minor was finally diagnosed.

Extramedullary hematopoiesis typically occurs as a compensatory mechanism, most frequently in the liver and spleen, in patients with hematologic disorders leading to deficient bone marrow function [1]. Paravertebral extramedullary hematopoiesis, either intrathoracic or retroperitoneal, is uncommon and is usually diagnosed with percutaneous CTguided needle aspiration/biopsy [2]. However, the increasing use of EUS or EUS with bronchoscope for the diagnosis of suspected paraesophageal lung cancer may seldom incidentally diagnose intrathoracic extramedullary hematopoiesis $[3,4]$. In a review of the literature, we identified a single case in which still EUS images of a paraesophageal, supradiaphragmatic extramedullary hematopoiesis were provided [5]. The bizarre B-mode "zebra-like" appearance of extra-
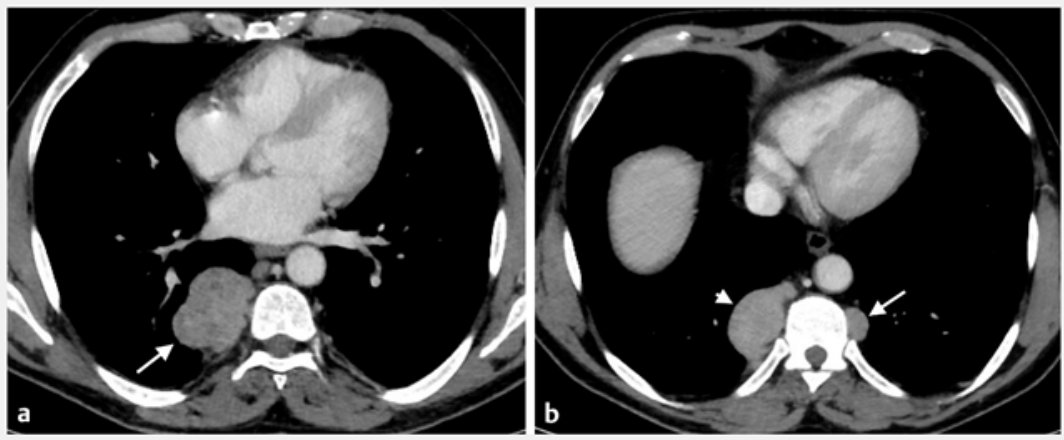

- Fig. 1 Axial computed tomography images of the chest. a A 5-cm, right-sided, paravertebral mass with areas of nonhomogeneous contrast enhancement (arrow). b The distal part of the right-sided mass (arrowhead) $2 \mathrm{~cm}$ more caudally, and a smaller contralateral nodular lesion (arrow).
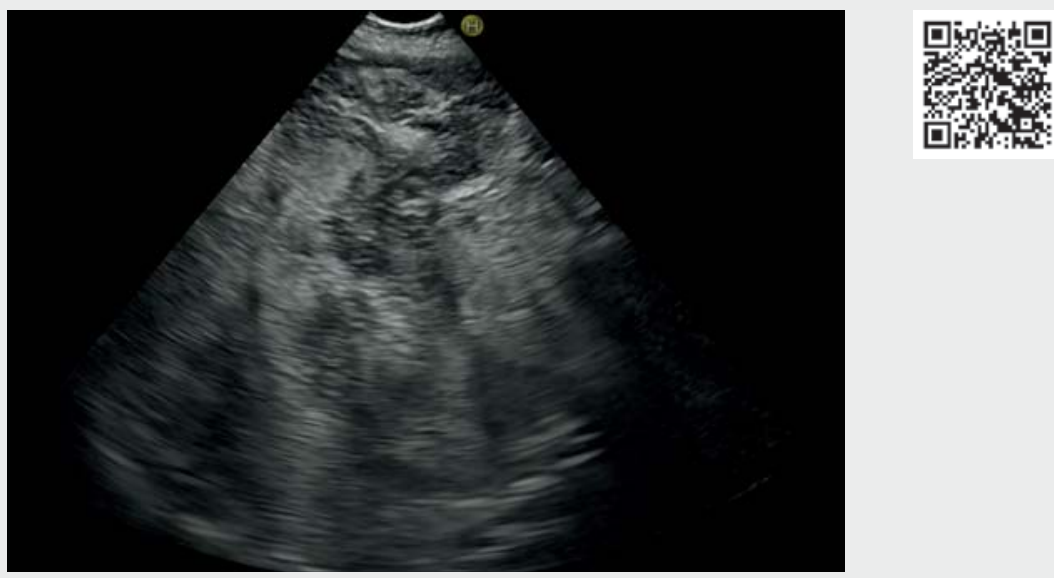

Video 1 B-mode video of endoscopic ultrasound with bronchoscope shows a $5.5-\mathrm{cm}$ mass characterized by heterogeneous echogenicity. In particular, the alternation of thick linear hyperechoic with iso-hypoechoic areas confers the mass a "zebra-like" appearance.

medullary hematopoiesis, thoroughly demonstrated in our video, might help the operator reliably suspect it in the correct clinical and radiological setting.

Endoscopy_UCTN_Code_CCL_1AF_2AC

\section{Competing interests}

The authors declare that they have no conflict of interest. 


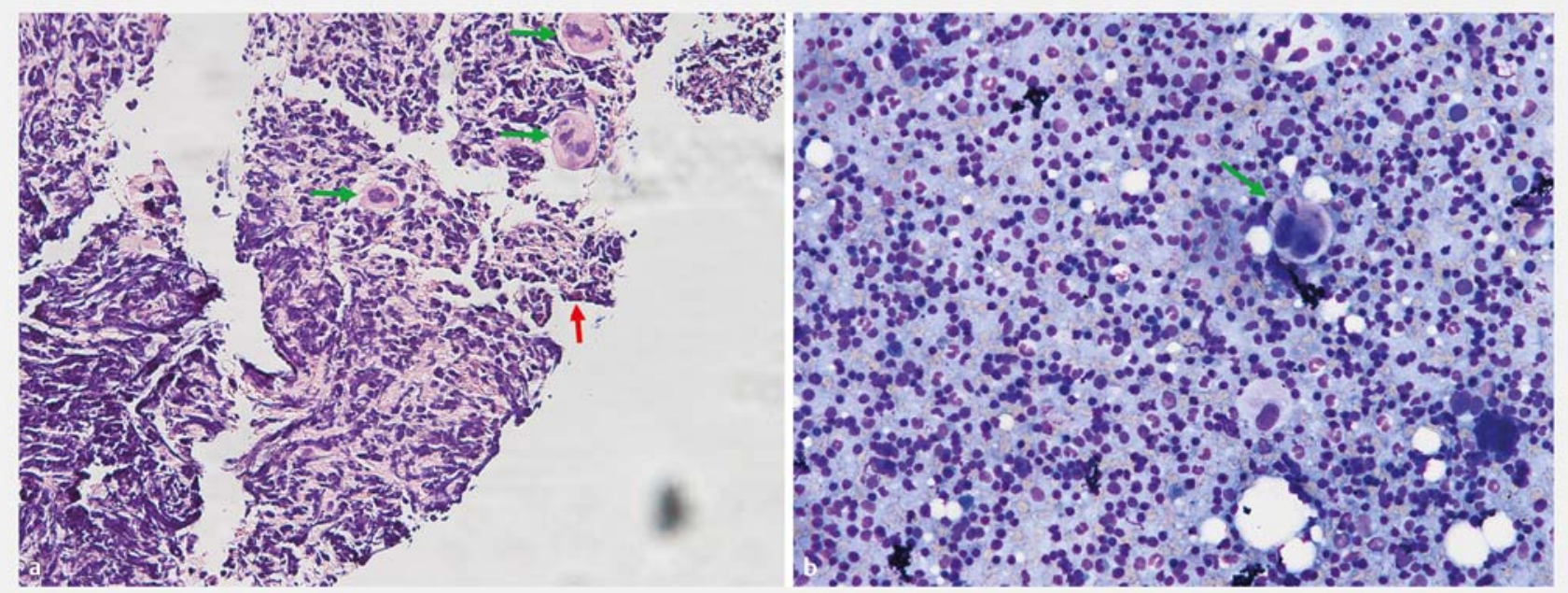

- Fig. 2 Pathological examination of specimens from bronchoscopic ultrasound-guided fine-needle aspiration. Some multinucleated megakaryocytes (green arrows) and rare myeloid elements (red arrow) are evident amidst lymphoid tissue. a As seen in tissue cores. $\mathbf{b}$ As seen in smears.

\section{The authors}

Rocco Trisolini ${ }^{1}$, Alberto Larghi² ${ }^{2}$, Vanina Livi ${ }^{3}$, Daniela Paioli ${ }^{3}$, Alessandra Cancellieri ${ }^{4}$

1 Interventional Pulmonology Unit,

Fondazione Policlinico Universitario A.

Gemelli IRCCS, Università Cattolica del Sacro

Cuore, Rome, Italy

2 Digestive Endoscopy Unit, Fondazione Policlinico Universitario A. Gemelli IRCCS, Rome, Italy

3 Interventional Pulmonology Unit, Fondazione Policlinico Universitario A. Gemelli IRCCS, Rome, Italy

4 Pathology Unit, Fondazione Policlinico Universitario A. Gemelli IRCCS, Rome, Italy

\section{Corresponding author}

\section{Rocco Trisolini, MD}

Interventional Pulmonology Unit, Fondazione Policlinico A. Gemelli, Università Cattolica del Sacro Cuore, Largo Agostino Gemelli 8, 00168, Rome, Italy rocco.trisolini@policlinicogemelli.it

\section{References}

[1] Roberts AS, Shetty AS, Melinick VM et al. Extramedullary hematopoiesis: radiological imaging features. Clin Radiol 2016; 71: 807814

[2] Kapatia G, Kaur A, Rastogi P et al. Extramedullary hematopoiesis: clinical and cytological features. Diagn Cytopathol 2020; 48: 191-196

[3] Korevaar DA, Colella S, Spijker R et al. Esophageal endosonography for the diagnosis of intrapulmonary tumors: a systematic review and meta-analysis. Respiration 2017; 93: 126-137

[4] Christiansen Skovgaard I, Kuijvenhoven JC, Bodtger $U$ et al. Endoscopic ultrasound with bronchoscope-guided fine needle aspiration for the diagnosis of paraesophageally located lung lesions. Respiration 2019; 97: 277283

[5] Camunha M, Carbonari A, Araujo J et al. A rare case of extramedullary hematopoiesis in the mediastinum diagnosed by endoscopic ultrasound. Endoscopy 2015; 47: E119-E120

\section{Bibliography}

Endoscopy 2022; 54: E172-E173

DOI 10.1055/a-1463-2527

ISSN 0013-726X

published online 28.4.2021

(c) 2021. Thieme. All rights reserved.

Georg Thieme Verlag KG, Rüdigerstraße 14,

70469 Stuttgart, Germany

\section{ENDOSCOPY E-VIDEOS}

https://eref.thieme.de/e-videos

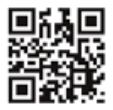

Endoscopy E-Videos is an open access online section, reporting on interesting cases and new techniques in gastroenterological endoscopy. All papers include a high quality video and all contributions are freely accessible online. Processing charges apply (currently EUR 375), discounts and wavers acc. to HINARI are available.

This section has its own submission website at https://mc.manuscriptcentral.com/e-videos 